\title{
N-3 polyunsaturated fatty acids attenuates triglyceride and inflammatory factors level in hfat- 1 transgenic pigs
}

Xingxing Liư, Daxin Pang ${ }^{\dagger}$, Ting Yuan, Zhuang Li, Zhanjun Li, Mingjun Zhang, Wenzhi Ren, Hongsheng Ouyang and Xiaochun Tang ${ }^{*}$

\begin{abstract}
Background: The consumption of $n-3$ polyunsaturated fatty acids (PUFAs) is important to human health, especially in cases of cardiovascular disease. Although beneficial effects of n-3 PUFAs have been observed in a number of studies, the mechanisms involved in these effects have yet to be discovered.

Methods: We generated hfat-1 transgenic pigs with traditional somatic cell nuclear transfer (SCNT) technology. The fatty acid composition in ear tissue of pigs were detected with gas chromatography. The cholesterol, triglycerides (TAG) and inflammation mediators in circulation were investigated.

Results: The hfat-1 transgenic pigs were developed which accumulate high levels of $n-3$ PUFAs than wild-types pigs. Gas chromatography results demonstrated that the total $n-3$ PUFAs in the ear tissues of the transgenic founders were 2 -fold higher than the wild-type pigs. A lipid analysis demonstrated that the levels of TAG in the transgenic pigs were decreased significantly. The basal levels of the inflammation mediators tumor necrosis factor-a (TNF-a), monocyte chemoattractant protein-1 (MCP-1) and interleukin-6 (IL-6) in transgenic pigs were inhibited markedly compared with the wild-type pigs.
\end{abstract}

Conclusions: These results suggest that $n-3$ PUFAs accumulation in vivo may have beneficial effects on vascular and hfat -1 transgenic pigs may be a useful tool for investigating the involved mechanisms.

Keywords: $n-3$ polyunsaturated fatty acids, Transgenic pig- fat-1, Inflammation, Triglyceride

\section{Background}

$\mathrm{N}-3$ polyunsaturated fatty acids (PUFAs) are important dietary fatty acids, including alpha-linolenic acid (ALA), eicosapentaenoic acid (EPA) and docosahexaenoic acid (DHA). ALA is enriched in seed oil and can be obtained directly through diets [1]. EPA and DHA can be converted from ALA through desaturation-chain elongation pathway in mammals $[2,3]$. Although young women has greater conversion capacity of ALA to DHA than men, the synthesis efficiency is still limited [4-8]. Thus, the primary source of this fatty acids for humans is dietary supplementation.

\footnotetext{
* Correspondence: xiaochuntang@jlu.edu.cn

${ }^{\dagger}$ Equal contributors

Jilin Provincial Model Animal Engineering Research Center, College of Animal Sciences, Jilin University, Xi'an Road, 5333\#, Jilin 130062, China
}

However, fat-1 gene in caenorhabditis elegans encodes an $n-3$ fatty acids desaturase which are able to convert $n-6$ to $n-3$ fatty acids by adding a double bond into n- 6 fatty acids at the $n-3$ hydrocarbon position $[9,10]$. Researchers developed transgenic mice, pigs and cows carrying the fat-1 gene previously and observed higher n-3 PUFAs accumulation in tissues [11-14].

A number of observational studies, clinical trials, and in vitro studies have demonstrated that the consumption of $n-3$ PUFAs is beneficial in the management of cardiovascular disease, including atherosclerosis, severe arrhythmias, and thrombosis, and decrease the incidence of cardiac arrest and sudden death [15-19]. Moreover, the American Heart Association (AHA) recommends that an intake of approximately $500 \mathrm{mg}$ /day of $n-3$ PUFAs be used to prevent cardiovascular disease (CVD) and that patients with CVD should have an intake of 
2-4 g/day [20-22]. In animals, accumulation of $n-3$ PUFAs in fat-1 transgenic mice decreased cholesterol level and body weight [23], attenuated vascular inflammation which represented by CD68 and neointimal hyperplasia [24], protected against global ischemia injury [25]. Moreover, decreased ratio of $n-6 / n-3$ in apo $E^{-1 /} / f a t-1$ mice reduced aortic lesion area significantly than that of $\mathrm{apoE}^{-1-}$ littermates [26].

Although rodents have been widely used in medical research as disease models, some of information that come from rodents still can not be replicated and has failed to translate into clinical practice. The pig has a heart size similar to that of humans, has a similar coronary circulation and can develop spontaneous atherosclerotic lesions [27-29]. Thus, to mimic the role of $n-3$ PUFAs in humans, we developed hfat-1 transgenic pigs and investigate the changes in cholesterol, TAG, and inflammation caused by the metabolism of $n-3$ PUFAs.

\section{Methods}

\section{Generation of transgenic pigs}

The hfat-1 expression plasmid with CAG promoter was donated by Dr. Dai (Nanjing Medical University, Jiangsu, China). The fat-1 gene is from C. elegans (GenBank: NM_001028389) and was optimized for mammal expression. The plasmid (Fig. 1) was linearized and transfected into primary fetal fibroblasts that were isolated from a Song-liao black pig using Fugene HD (Roche, Basel, Switzerland). After $24 \mathrm{~h}$ of transfection, the cells were split 1:36 and cultured in selection medium con-

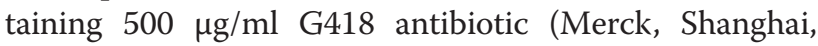
China). After 10 days of selection, the surviving cell colonies were propagated in 24-well plates with $200 \mu \mathrm{g} /$ ml G418 antibiotic for another 4 days. G418 resistant clones were analyzed with PCR assays (Tiangen, Beijing, China) using the following primers: hfat-1 identi forward (GGA CCT GGT GAA GAG CAT CCG) and hfat-1 identi reverse (GCC GTC GCA GAA GCC AAA C) located in the hfat-1 gene and neo identi forward (ATG ATT GAA CAA GAT GGA TTG CAC GC) and neo identi reverse (TCA GAA GAA CTC GTC AAG AAA GGC GAT AG) located in the neomycin gene. The PCR assays were conducted using 30 cycles of denaturation at $94{ }^{\circ} \mathrm{C}$ for $30 \mathrm{~s}$, annealing at 55 and $50{ }^{\circ} \mathrm{C}$ for $30 \mathrm{~s}$, and extension at $72{ }^{\circ} \mathrm{C}$ for $90 \mathrm{~s}$. The PCR products were analyzed by electrophoresis and sequencing to confirm the integrity of the hfat-1 gene within the pig genome in the G418 resistant clones. The five identified positive colonies were selected as donor cells to perform somatic cell nuclear transfer (SCNT) and embryo transfer as previously described [30]. The pigs housed in a $18-20^{\circ} \mathrm{C}$ environment in winter with free access to water and were fed three times per day (morning, 6:00; noon, 13:00; evening, 17:30) with a diet containing crude protein 15 $\%$ and crude fat $4 \%$. All the animal experiments and maintenance protocols were in accordance with the Guide for the Care and Use of Laboratory Animals and were approved by Jilin University.

\section{Genotype and tissue fatty acid analysis of the founders}

Genomic DNA from the cloned piglets was extracted from the tails and subjected to PCR analysis to confirm the insertion of the hfat-1 gene using the hfat-1 identi forward and reverse primers. The PCR products were analyzed by electrophoresis and sequencing. The fatty acid composition in the ears which selected according to the previous research of the transgenic founders was analyzed using gas chromatography-mass spectrometry (GC-MS) (6890 N, Agilent, USA) method as described in other reports [13,31,32]. The initial temperature of the program was $160{ }^{\circ} \mathrm{C}$ for $2 \mathrm{~min}$, then increased at a rate of $1{ }^{\circ} \mathrm{C} / \mathrm{min}$ to $210{ }^{\circ} \mathrm{C}$ for $50 \mathrm{~min}$. The fatty acid concentration is presented as a percentage of the total fat in the ears. Each value represents the mean \pm standard deviation. Each sample measurement was performed three times.

\section{Quantitative real-time PCR}

Blood was collected from pigs using anticoagulant EDTA tubes, and peripheral blood mononuclear cells (PBMCs) were isolated from the whole blood with Histopaque1077(Sigma Inc., USA) according to the manufacturer's instructions. Briefly, add $5 \mathrm{ml}$ Histopaque-1077 into $50 \mathrm{ml}$ tube, carefully add $5 \mathrm{ml}$ blood onto Histopaque1077, centrifuge at $400 \times \mathrm{g}$ for $30 \mathrm{~min}$, carefully transfer the opaque interface which containing PBMCs into a new tube. Total RNA was isolated from the PBMCs (five transgenic pigs and three wild-type pigs) using the TRIzol- $\mathrm{A}^{+}$reagent (Tiangen, Beijing, China) according to the manufacturer's instructions. First-strand cDNAs were synthesized from $1 \mu \mathrm{g}$ of total RNA using a BioRT cDNA first stand synthesis kit (Bioer,

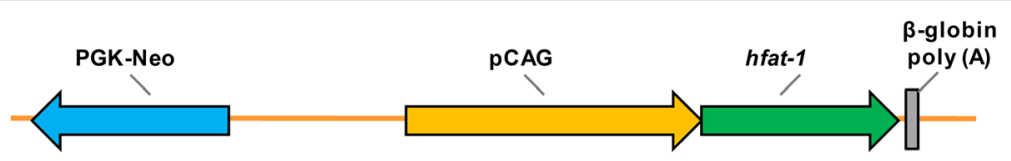

Fig. 1 The expression cassette, mainly including the PCAG promoter, humanized fat-1 gene, and a neomycin selection cassette 
Hangzhou, China), and the samples were analyzed with a Bioeasy SYBR green I real-time PCR kit (Bioer, Hangzhou, China). The detection of inflammation mediators were performed using the following primers: pMCP-1 forward (TCACCAGCAGCAAGTGTCCT) and pMCP-1 reverse (ATGTGCCCAAGTCTCCGTTT); pIL6 forward (TGGGTTCAATCAGGAGAC) and pIL-6 reverse (CTGACCAGAGGAGGGAAT); pTNF- $\alpha$ forward (CGCATCGCCGTCTCCTACCA) and pTNF- $\alpha$ reverse (TGCCCAGATTCAGCAAAGTCCA). The gene expression was normalized against the internal control $(\beta$-actin).

\section{Plasma lipid and lipoprotein analysis}

After $16 \mathrm{~h}$ of food deprivation, $5 \mathrm{ml}$ of blood was obtained from precaval vein of each pig. Centrifuge at $1000 \times \mathrm{g}$ for $10 \mathrm{~min}$ to obtain plasma. The TAG, total cholesterol (TC), HDL-C and LDL-C levels in each sample were determined by corresponding kit (ERKN, Zhejiang, China) and analyzed using Beckman coulter UniCel DxC 800 Synchron (Beckman coulter, USA) by No. 208 Hospital of the People's Liberation Army.

\section{Statistical analysis}

Data in Figs. 3 and 4 are expressed as the mean \pm SEM. Comparisons were performed using an unpaired twotailed Student's $t$-test unless otherwise specified. Data were analyzed using GraphPad Prism6. $P<0.05$ was considered to be statistically significant.

\section{Results}

\section{Generation of hfat-1 transgenic pigs}

Unlike the development of transgenic mice which use embryonic stem cells (ES) for preselection of gene insertion [33], primary embryonic pig fibroblasts were employed for transfection with a linearized hfat-1 expression plasmid. The screening for positive cells was performed in G418-containing culture medium for 10 days; 50 G418 -resistant clones were picked and analyzed via PCR for the integration of hfat-1 cDNA. Thirty clones exhibited both the expected 458 bp band of hfat-1 and the 790 bp band of the neomycin sequence (data not shown); 5 of these clones were selected for presentation in this paper and for individually performing somatic SCNT in the following step (Fig. 2a and b).

On average, 248 reconstructed embryos from each positive clone were transferred into each naturally cycling gilt, and totally five recipients. At days 25-28, 2 recipients (40\%) became pregnant, as determined by ultrasound scanning. One of these aborted at 29 days, and one pregnancy went to term (20\%). Five piglets were born by natural delivery. The cloning efficiency was $0.4 \%$ (No. of piglets/No. of embryos transferred). The genomic PCR assay was performed using DNA extracted from the tail tissue, and the
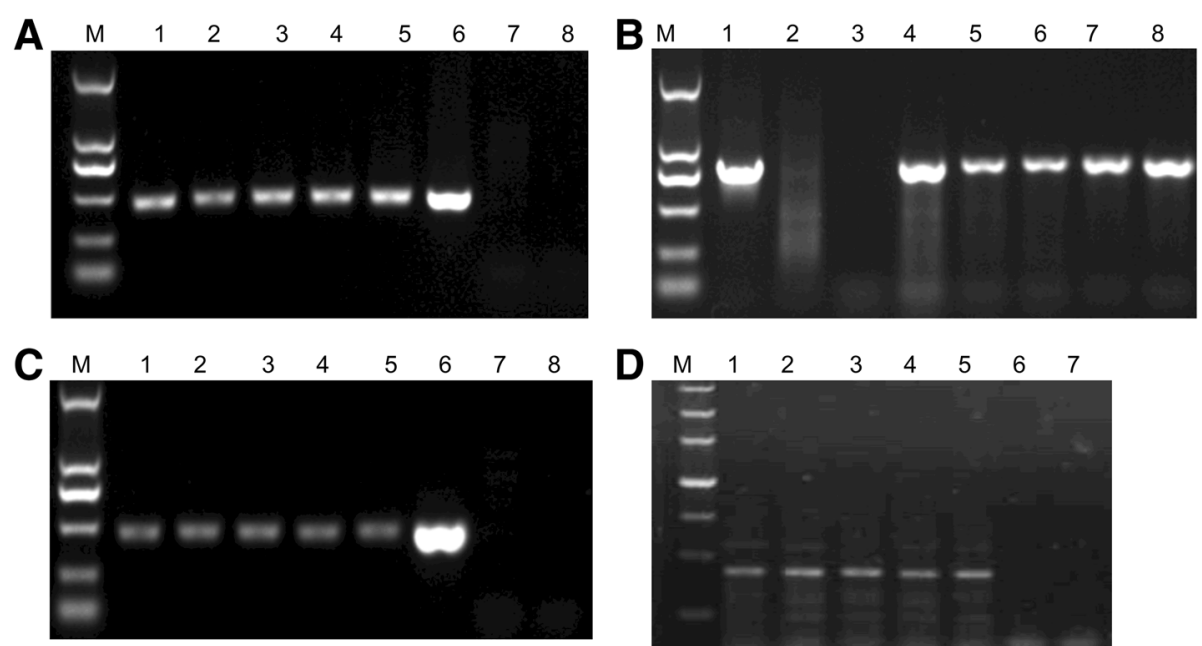

Fig. 2 Identification of G418-resistant clones and hfat-1 transgenic pigs. Analyse of the hfat-1 gene and neomycin gene integration into the pig genome in the G418-resistant clones were performed using a PCR assay with the primer pairs of hfat-1 identi (458 bp) (a) and neo identi (790 bp) (b). a 1-5, five G418-resistant clones, on which SCNT was individually performed in the following procedure. 6, hfat-1 plasmid as a positive control. 7-8, negative controls. b 1, hfat-1 plasmid as a positive control. 2-3, negative controls. 4-8, five G418-resistant clones. The hfat-1 gene integration into the pig genome and transcription in the transgenic pigs were analyzed using PCR (c) and RT-PCR (d), respectively, with the hfat-1 identi primer pair (458 bp). c 1-5, five hfat-1 transgenic pigs. 6, hfat-1 plasmid as a positive control. 7-8, two wild-type pigs. d 1-5, five hfat-1 transgenic pigs. 6-7, two wild-type pigs 
Table 1 Statistical analyses were performed using an unpaired two-tailed Student's t-test

\begin{tabular}{|c|c|c|}
\hline Fatty acid in ears & Transgenic piglets $(n=5)$ & Wild-type piglets $(n=3)$ \\
\hline $18: 3 n-3(\%)$ & $2.25 \pm 0.15$ & $1.12 \pm 0.09$ \\
\hline 20:5 n-3 (\%) (EPA) & $2.71 \pm 0.72$ & $1.09 \pm 0.12$ \\
\hline $22: 5 n-3(\%)$ & $1.23 \pm 0.21$ & $0.51 \pm 0.06$ \\
\hline $22: 6$ n-3 (\%) (DHA) & $1.15 \pm 0.17$ & $0.38 \pm 0.08$ \\
\hline $18: 2 n-6(\%)$ & $3.28 \pm 0.25$ & $5.72 \pm 0.64$ \\
\hline $20: 4$ n-6 (\%) & $5.78 \pm 0.57$ & $5.65 \pm 0.39$ \\
\hline $22: 5 n-6(\%)$ & $1.19 \pm 0.22$ & $2.22 \pm 0.16$ \\
\hline Total n-3 FA (\%) ${ }^{\mathrm{a}}$ & $7.34 \pm 0.76$ & $3.10 \pm 0.06$ \\
\hline Total n-6 FA (\%) & $10.25 \pm 2.28$ & $13.59 \pm 0.24$ \\
\hline$n-6 / n-3$ ratio $^{a}$ & $1.81 \pm 0.41$ & $4.38 \pm 0.64$ \\
\hline
\end{tabular}

${ }^{a} P<0.01$ Table $1 n-3$ and $n-6$ fatty acids concentration and $n-6 / n-3$ ratios in ear samples from hfat-1 transgenic pigs and wild-type pigs

results show that all five piglets were positive for the hfat-1 transgene (Fig. 2c).

\section{Accumulation of $n-3$ PUFAs in the transgenic pigs}

To examine whether hfat-1 was transcribed in the transgenic pigs, reverse transcription PCR was performed using cDNA obtained from the tail. The results show that hfat-1 was transcribed in all five of hfat-1 positive transgenic pigs (Fig. 2d). To investigate whether the transfected hfat-1 gene was functional in the transgenic pigs, gas chromatography was performed to determine the composition of the PUFAs. The fatty acid profiles in Table 1 were derived from the ear tissues of five transgenic pigs and three wild-type pigs. The total $n-3$ PUFAs in the ear tissues of the transgenic founders were 2-fold higher than those of the wild-type pigs. However, the $n-6$ PUFAs of the transgenic founders were not significantly altered, and the ratio of $n-6 / n-3$ fatty acids was reduced 2 -fold in the transgenic founders compared with the wild-type pigs.

\section{Lipid analysis of the hfat- 1 transgenic pigs}

There were no difference of body weight between wildtype and transgenic pigs (Fig. 3a). To examine whether an abundance of $n$-3 PUFAs is beneficial to the vasculature, the cholesterol and TAG concentrations in the blood of one-year-old transgenic and wild-type pigs were measured. The results demonstrated that TC was not different between transgenic and wild-type pigs in fasting states (Fig. 3b). HDL-C and LDL-C levels were also not significantly altered under the same conditions (Fig. 3c and d). However, the level of TAG in hfat-1 transgenic pigs was decreased significantly compared with the wild-type pigs (Fig. 3e).
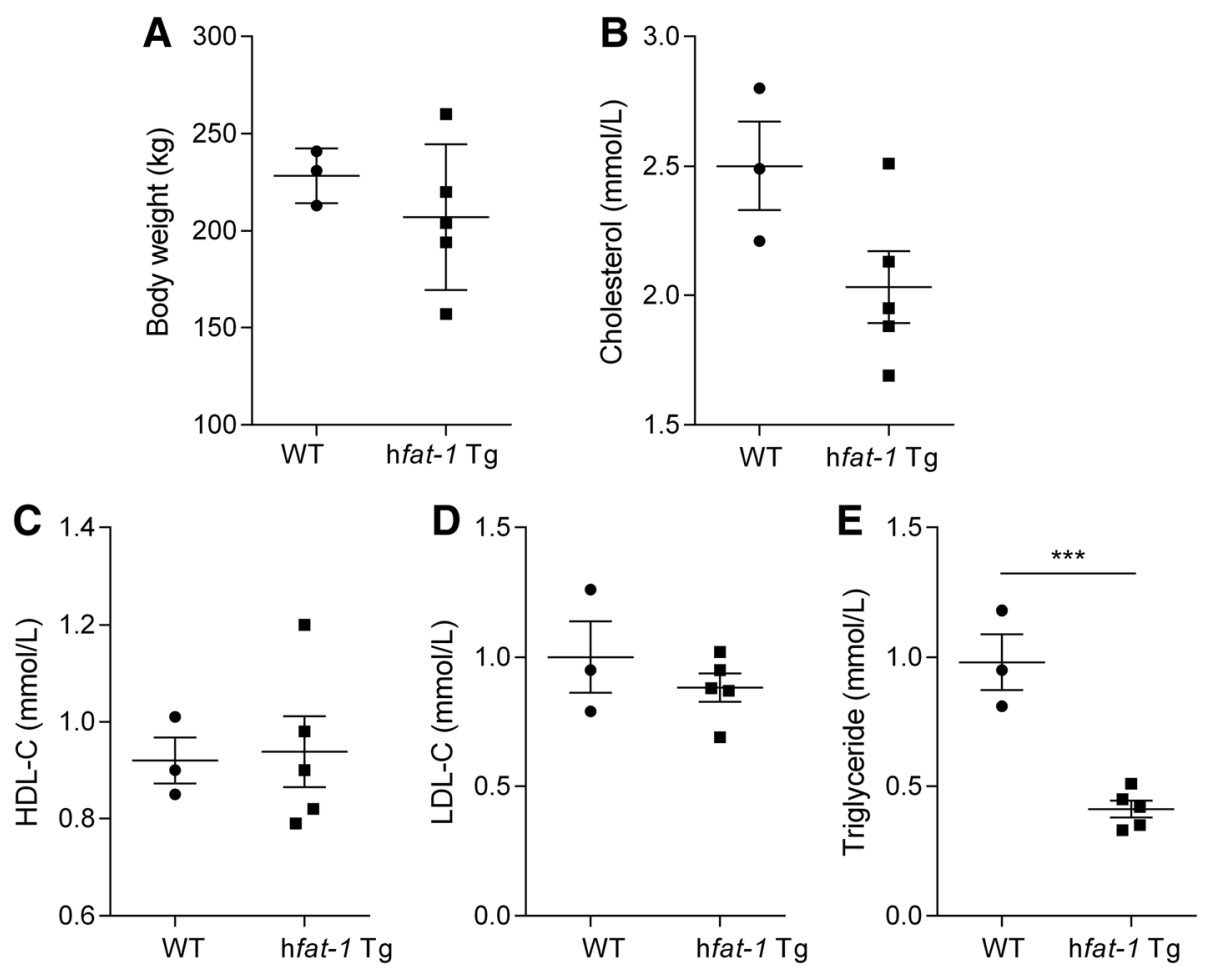

Fig. 3 The body weight and plasma characters. a The body weight of wild-type and hfat-1 transgenic pigs at 18 month. Plasma was isolated from the blood of the transgenic and wild-type pigs after $16 \mathrm{~h}$ of food deprivation and assayed for TC (b), HDL-C (c), LDL-C (d), and TG (e). ${ }^{* *}, p<0.001$ 
Inflammatory factors analysis of the hfat-1 transgenic pigs Because cardiovascular disease correlates with chronic inflammation, the transcription and concentration of inflammation genes were measured with a real-time PCR assay using PBMCs cDNA and with Elisa using plasma of the transgenic and wild-type pigs. The result shows that MCP-1, IL-6 and TNF- $\alpha$ mRNA levels were reduced obviously in the transgenic pigs compared with the wild-type pigs (Fig. 4a, b and c). In accordance with the transcription level, the concentrations of MCP-1, IL-6 and TNF- $\alpha$ were decreased significantly as well. These results indicate that an abundance of $n$-3 PUFAs is beneficial for maintaining a lower level of inflammation in the body, which is consistent with previous research $[24,26,34]$.

\section{Discussion}

N-3 PUFAs are important for human health. Moreover, meat products usually have less $n-3$ and more $n-6$ PUFAs. The imbalance of $n-6 / n-3$ intake contribute to the development of CVD $[18,35]$. In this study, we introduced the $n-3$ fatty acid desaturase encoding gene fat-1 from $C$.elegans into the pig using SCNT technology, and the gene was successfully expressed in the transgenic pigs. The cholesterol, TAG and inflammatory cytokines of hfat-1 transgenic pigs were determined.

The hfat-1 transgenic pigs in our study were cloned from one G418 resistant clone for more stable gene expression and accumulation of fatty acids. The concentrations of total $n-3$ PUFAs in the ear tissues of our transgenic founders were two-fold higher than in the wild-type pigs, but the n-6 PUFAs were less altered. Additionally, the EPA and DHA levels showed a 2-fold and 3 -fold increase in the transgenic founders, respectively. Consequently, the ratio of $n-6 / n-3$ fatty acids was decreased two-fold in the transgenic founders compared with wild-type pigs. In a previous study, Saeki et al. got $20 \%$ more linoleic acid (omega-6 PUFA) in adipose tissue in $\triangle 12$ fatty acid desaturase gene transgenic pigs [36]. Lai et al. reported that the levels of $n-3$ PUFAs in the tail tissues of transgenic pigs were three-fold higher than those in wild-type pigs, and the ratio of $n-6 / n-3$ fatty acids was reduced five-fold in the transgenic pigs [14]; Zhou et al. reported that the level of $n-3$ PUFAs in the muscle tissues of $c b r-f a t-1$ transgenic pigs was sixfold higher than that of the wild-type pigs and the ratio of $n-6 / n-3$ fatty acids was reduced 10.5 fold in the transgenic founders [11]. However, the accumulation of $n-3$
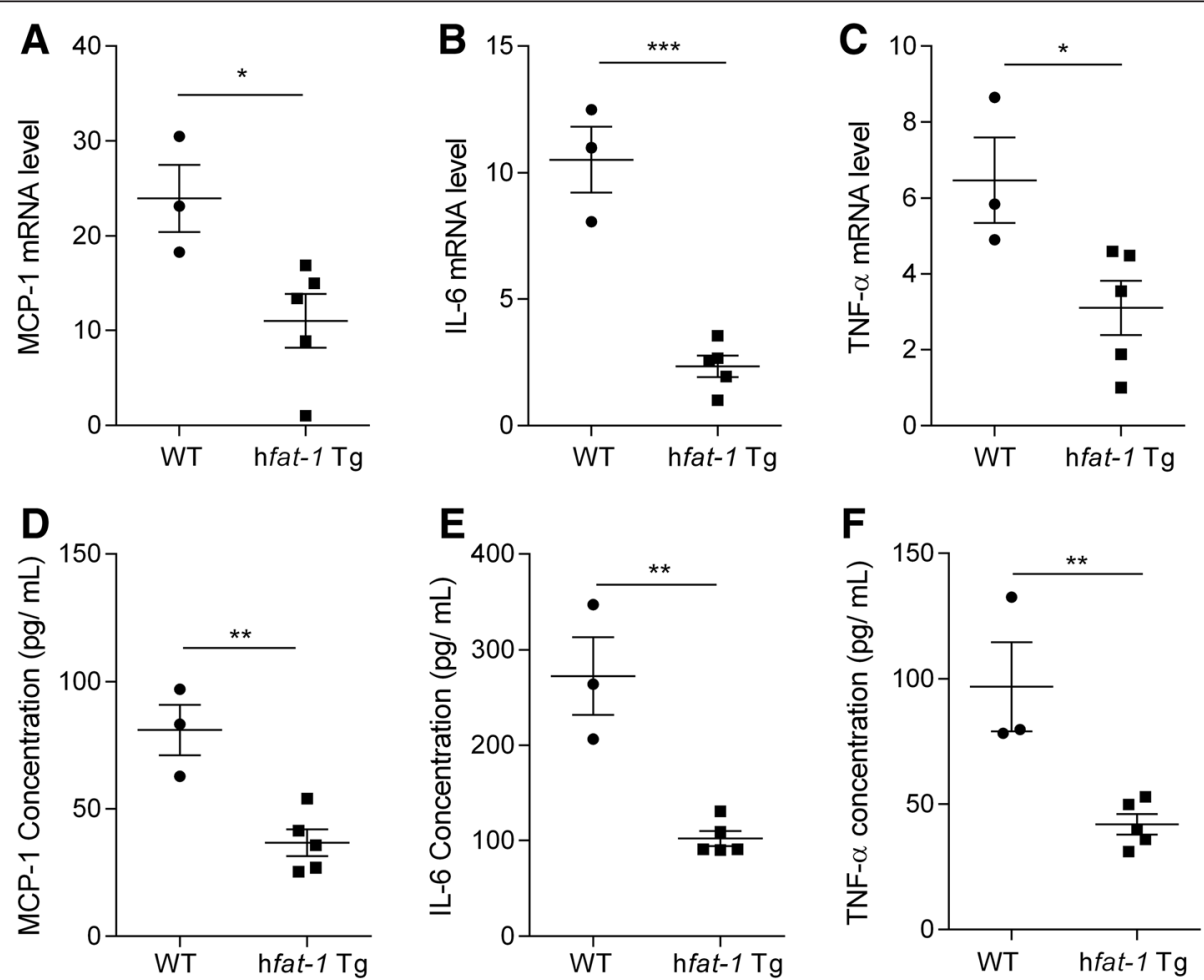

Fig. 4 The levels of proinflammatory cytokines in hfat-1 transgenic pigs. Total RNA was isolated from the blood monoyte of transgenic and wild-type pigs and qRT-PCR was performed. a-c MCP-1, IL-6 and TNF-a mRNA level in transgenic and wild-type pigs. Plasma was isolated from the blood of the transgenic and wild-type pigs and MCP-1, IL-6 and TNF-a concentration were analysed by Elisa. d-f MCP-1, IL-6 and TNF- $a$ concentration in transgenic and wild-type pigs. All data are presented as the mean \pm SEM (five transgenic pigs and three wild-type pigs) ${ }^{*}, P<0.01$. ${ }^{* *}, P<0.001$ 
PUFAs is not as high and the ratio of $n-6 / n-3$ PUFAs is not altered as much in our results as in previous reports.

In fat- 1 transgenic mice, decreased HDL-C, LDL-C, TC and TAG were observed, but the body weight is not uniform [23, 37]. In the hfat-1 transgenic pig, there was no difference observed in body weight compared to wild-type pigs. A high level of TAG is supposed to be an independent risk factor of coronary heart disease (CHD) according to AHA reports [20,38]. As pigs, the basal TAG levels in Song-liao black is higher compared with other miniature pigs (data not shown). In the hfat-1 transgenic pigs, the accumulation of $n-3$ PUFAs lowered the TAG levels significantly in circulation in a fasting states compared with the levels in the wild-type pigs. In addition, plasma TC and HDL-C were not changed in the transgenic pigs. Plasma LDL-C was not statistically decreased. Therefore, the lowered TAG levels might exert some protective effects in the hfat-1 transgenic pig.

Chronic inflammation plays an important role in the progression of cardiovascular disease. A number of studies have reported that EPA and DHA or fish oil inhibit endotoxin-induced IL-6, TNF- $\alpha$ and IL-1.production in vitro and in vivo [39-42]. In the hfat-1 transgenic pigs, the basal mRNA levels of the inflammation mediators IL-6, TNF- $\alpha$ and MCP-1 were inhibited compared with those of the wild-type pigs. In accordance with the mRNA level, the concentrations of MCP-1, IL- 6 and TNF- $\alpha$ were decreased significantly as well. Therefore, the anti-inflammatory effects of $n-3$ PUFAs may contribute to the lower inflammation levels in mammals.

Although the accumulation of $n-3$ PUFAs in our transgenic pigs was not as high as previous reports, the TAG and inflammatory factor levels were decreased indeed under similar total $n-3$ plus $n-6$ PUFAs levels. The results illustrated that moderate alteration of $n-6 / n-3$ PUFAs ratio is enough to affect metabolism in mammals.

\section{Conclusions}

We obtained hfat-1 transgenic pigs that accumulate higher levels of $n-3$ PUFAs than do wild-type pigs. The $n$-3 PUFAs in the ear tissues of the transgenic founders were 2 -fold higher than those of the wildtype pigs. TAG levels in the hfat-1 transgenic pigs were decreased significantly, whereas TC, HDL-C and LDL-C were not statistically different. However, the levels of the inflammatory mediators IL-6, TNF- $\alpha$ and MCP-1 were decreased significantly as well. Therefore, $n$-3 PUFAs supplementation in human daily life may have protective effects on vascular.

\section{Abbreviations}

IL-6: interleukin-6; MCP-1: monocyte chemoattractant protein-1; PBMCs: peripheral blood monouclear cells; PUFAs: polyunsaturated fatty acids; TAG: triglycerides;

TNF-a: tumor necrosis factor-a.

\section{Competing interests}

The authors declare that they have no competing interests.

\section{Authors' contributions}

DP and WR conceived the study. XL, TY carried out the experiment. ZL, MZ and ZJL provide technical support for transgenic pig experiment. $\mathrm{HO}$ and $\mathrm{XT}$ performed analysis and drafted the first manuscript and given the final approval. All authors read and approved the final manuscript.

\section{Acknowledgments}

This work was supported by grants from Cultivation and Breeding of New Transgenic Organisms (No. 2014ZX0800604B), and the National Natural Science Foundation of China (No. 31472053). We thank Dr. Dai of Nanjing Medical University for assistance with the measurement of fatty acid composition and thank Tingting Yu, Qiangbing Yang, Shengnan Sun and Li Shen for the technical assistance of pig related experiments.

Received: 6 February 2016 Accepted: 3 May 2016

Published online: 10 May 2016

\section{References}

1. Cunnane SC, Ganguli S, Menard C, Liede AC, Hamadeh MJ, Chen ZY, Wolever TM, Jenkins DJ. High alpha-linolenic acid flaxseed (Linum usitatissimum): some nutritional properties in humans. Br J Nutr. 1993;69: 443-53.

2. Igarashi M, DeMar Jr JC, Ma K, Chang L, Bell JM, Rapoport SI. Upregulated liver conversion of alpha-linolenic acid to docosahexaenoic acid in rats on a 15 week n-3 PUFA-deficient diet. J Lipid Res. 2007:48:152-64.

3. Bazinet RP, McMillan EG, Cunnane SC. Dietary alpha-linolenic acid increases the n-3 PUFA content of sow's milk and the tissues of the suckling piglet. Lipids. 2003;38:1045-9.

4. Burdge GC, Wootton SA. Conversion of alpha-linolenic acid to eicosapentaenoic, docosapentaenoic and docosahexaenoic acids in young women. Br J Nutr. 2002;88:411-20.

5. Plourde M, Cunnane SC. Extremely limited synthesis of long chain polyunsaturates in adults: implications for their dietary essentiality and use as supplements. Appl Physiol Nutr Metab. 2007:32:619-34.

6. Burdge GC, Calder PC. Conversion of alpha-linolenic acid to longer-chain polyunsaturated fatty acids in human adults. Reprod Nutr Dev. 2005:45:581-97.

7. Burdge G. Alpha-linolenic acid metabolism in men and women: nutritional and biological implications. Curr Opin Clin Nutr Metab Care. 2004;7:137-44.

8. Giltay EJ, Gooren LJG, Toorians AWFT, Katan MB, Zock PL. Docosahexaenoic acid concentrations are higher in women than in men because of estrogenic effects. Am J Clin Nutr. 2004:80:1167-74.

9. Spychalla JP, Kinney AJ, Browse J. Identification of an animal omega-3 fatty acid desaturase by heterologous expression in Arabidopsis. Proc Natl Acad Sci U S A. 1997;94:1142-7.

10. Kang JX. From fat to fat-1: a tale of omega-3 fatty acids. J Membr Biol. 2005; 206:165-72

11. Zhou $Y$, Lin $Y$, Wu $X$, Feng $C$, Long $C$, Xiong F, Wang $N$, Pan D, Chen $H$. The high-level accumulation of $n-3$ polyunsaturated fatty acids in transgenic pigs harboring the $n-3$ fatty acid desaturase gene from Caenorhabditis briggsae. Transgenic Res. 2014;23:89-97.

12. Clarke SE, Kang JX, Ma DW. The iFat1 transgene permits conditional endogenous n-3 PUFA enrichment both in vitro and in vivo. Transgenic Res. 2014;23:489-501.

13. Wu X, Ouyang H, Duan B, Pang D, Zhang L, Yuan T, Xue L, Ni D, Cheng L, Dong $S$, et al. Production of cloned transgenic cow expressing omega-3 fatty acids. Transgenic Res. 2012;21:537-43.

14. Lai L, Kang JX, Li R, Wang J, Witt WT, Yong HY, Hao Y, Wax DM, Murphy CN, Rieke A, et al. Generation of cloned transgenic pigs rich in omega-3 fatty acids. Nat Biotechnol. 2006;24:435-6.

15. Rangel-Huerta OD, Aguilera CM, Mesa MD, Gil A. Omega-3 long-chain polyunsaturated fatty acids supplementation on inflammatory biomakers: a systematic review of randomised clinical trials. Br J Nutr. 2012;107 Suppl 2: S159-170.

16. Lee $J H$, O'Keefe $\mathrm{JH}$, Lavie CJ, Harris WS. Omega-3 fatty acids: cardiovascular benefits, sources and sustainability. Nat Rev Cardiol. 2009;6:753-8.

17. Macchia A, Levantesi G, Franzosi MG, Geraci E, Maggioni AP, Marfisi R, Nicolosi GL, Schweiger C, Tavazzi L, Tognoni G, et al. Left ventricular systolic dysfunction, total mortality, and sudden death in patients with myocardial 
infarction treated with n-3 polyunsaturated fatty acids. Eur J Heart Fail. 2005; 7:904-9.

18. Valagussa F, Marchioli R, Barzi F, Pagliaro L, Campolo L, Cericola A, Mocarelli P, Casari A, Di Minno G, B Donati M, et al. Dietary supplementation with n-3 polyunsaturated fatty acids and vitamin $\mathrm{E}$ after myocardial infarction: results of the GISSI-Prevenzione trial. Gruppo Italiano per lo Studio della Sopravvivenza nell'Infarto miocardico. Lancet. 1999;354:447-455.

19. Marchioli R, Barzi F, Bomba E, Chieffo C, Di Gregorio D, Di Mascio R, Franzosi MG, Geraci E, Levantesi G,Maggioni AP et al. Early protection against sudden death by $\mathrm{n}-3$ polyunsaturated fatty acids after myocardial infarction: time-course analysis of the results of the Gruppo Italiano per lo Studio della Sopravvivenza nell'Infarto Miocardico (GISSI)-Prevenzione. Circulation. 2002;105:1897-903.

20. Miller M, Stone NJ, Ballantyne C, Bittner V, Criqui MH, Ginsberg HN, Goldberg AC, Howard WJ, Jacobson MS, Kris-Etherton PM, et al. Triglycerides and cardiovascular disease: a scientific statement from the American Heart Association. Circulation. 2011;123:2292-333.

21. Lavie CJ, Milani RV, Mehra MR, Ventura HO. Omega-3 polyunsaturated fatty acids and cardiovascular diseases. J Am Coll Cardiol. 2009:54:585-94.

22. Kris-Etherton PM, Harris WS, Appel $\amalg$, Association AH, Nutrition C. Fish consumption, fish oil, omega-3 fatty acids, and cardiovascular disease. Circulation. 2002;106:2747-57.

23. Ma S, Ge Y, Gai X, Xue M, Li N, Kang J, Wan J, Zhang J. Transgenic n-3 PUFAs enrichment leads to weight loss via modulating neuropeptides in hypothalamus. Neurosci Lett. 2016;611:28-32.

24. Li X, Ballantyne LL, Che X, Mewburn JD, Kang JX, Barkley RM, Murphy $R C$, Yu Y, Funk CD. Endogenously generated omega-3 fatty acids attenuate vascular inflammation and neointimal hyperplasia by interaction with free fatty acid receptor 4 in mice. J Am Heart Assoc. 2015;4.

25. Luo C, Ren H, Wan JB, Yao X, Zhang X, He C, So KF, Kang JX, Pei Z, Su H. Enriched endogenous omega-3 fatty acids in mice protect against global ischemia injury. J Lipid Res. 2014;55:1288-97.

26. Wan JB, Huang LL, Rong R, Tan R, Wang J, Kang JX. Endogenously decreasing tissue $n-6 / n-3$ fatty acid ratio reduces atherosclerotic lesions in apolipoprotein E-deficient mice by inhibiting systemic and vascular inflammation. Arterioscler Thromb Vasc Biol. 2010;30:2487-94.

27. Swindle MM, Makin A, Herron AJ, Clubb Jr FJ, Frazier KS. Swine as models in biomedical research and toxicology testing. Vet Pathol. 2012; 49:344-56.

28. Garbern JC, Mummery CL, Lee RT. Model systems for cardiovascular regenerative biology. Cold Spring Harb Perspect Med. 2013;3:a014019.

29. Paslawski R, Paslawska U, Szuba A, Nicpon J. Swine as a Model of Experimental Atherosclerosis. Adv Clin Exp Med. 2011;20:211-5.

30. Luo W, Li Z, Huang Y, Han Y, Yao C, Duan X, Ouyang H, Li L. Generation of AQP2-Cre transgenic mini-pigs specifically expressing Cre recombinase in kidney collecting duct cells. Transgenic Res. 2014;23:365-75.

31. Zhu G, Chen H, Wu X, Zhou Y, Lu J, Deng J. A modified n-3 fatty acid desaturase gene from Caenorhabditis briggsae produced high proportion of DHA and DPA in transgenic mice. Transgenic Res. 2008;17:717-25.

32. Yu M, Gao Q, Wang Y, Zhang W, Li L, Wang Y, Dai Y. Unbalanced omega-6/ omega-3 ratio in red meat products in China. J Biomed Res. 2013;27:366-71.

33. Limaye A, Hall B, Kulkarni AB. Manipulation of mouse embryonic stem cells for knockout mouse production. Curr Protoc Cell Biol. 2009;Chapter 19:Unit 19131913 11-24

34. Yan Y, Jiang W, Spinetti T, Tardivel A, Castillo R, Bourquin C, Guarda G, Tian Z, Tschopp J, Zhou R. Omega-3 fatty acids prevent inflammation and metabolic disorder through inhibition of NLRP3 inflammasome activation. Immunity. 2013;38:1154-63.

35. Sheard NF. Fish consumption and risk of sudden cardiac death. Nutr Rev. 1998:56:177-9.

36. Saeki K, Matsumoto K, Kinoshita M, Suzuki I, Tasaka Y, Kano K, Taguchi Y, Mikami K, Hirabayashi M, Kashiwazaki N, et al. Functional expression of a Delta12 fatty acid desaturase gene from spinach in transgenic pigs. Proc Natl Acad Sci U S A. 2004;101:6361-6.

37. White PJ, Mitchell PL, Schwab M, Trottier J, Kang JX, Barbier O, Marette A. Transgenic omega-3 PUFA enrichment alters morphology and gene expression profile in adipose tissue of obese mice: Potential role for protectins. Metabolism. 2015;64:666-76.
38. Patel A, Barzi F, Jamrozik K, Lam TH, Ueshima H, Whitlock G, Woodward M. Serum triglycerides as a risk factor for cardiovascular diseases in the Asia-Pacific region. Circulation. 2004;110:2678-86.

39. Li H, Ruan XZ, Powis SH, Fernando R, Mon WY, Wheeler DC, Moorhead JF, Varghese Z. EPA and DHA reduce LPS-induced inflammation responses in HK-2 cells: evidence for a PPAR-gamma-dependent mechanism. Kidney Int. 2005;67:867-74.

40. Weylandt KH, Nadolny A, Kahlke L, Kohnke T, Schmocker C, Wang J, Lauwers GY, Glickman JN, Kang JX. Reduction of inflammation and chronic tissue damage by omega-3 fatty acids in fat- 1 transgenic mice with pancreatitis. Biochim Biophys Acta. 2008;1782:634-41.

41. Mishra A, Chaudhary A, Sethi S. Oxidized omega-3 fatty acids inhibit NF-kappaB activation via a PPARalpha-dependent pathway. Arterioscler Thromb Vasc Biol. 2004;24:1621-7.

42. Schmocker C, Weylandt KH, Kahlke L, Wang J, Lobeck H, Tiegs G, Berg T, Kang JX. Omega-3 fatty acids alleviate chemically induced acute hepatitis by suppression of cytokines. Hepatology. 2007:45:864-9.

\section{Submit your next manuscript to BioMed Central and we will help you at every step:}

- We accept pre-submission inquiries

- Our selector tool helps you to find the most relevant journal

- We provide round the clock customer support

- Convenient online submission

- Thorough peer review

- Inclusion in PubMed and all major indexing services

- Maximum visibility for your research

Submit your manuscript at www.biomedcentral.com/submit
(O) BioMed Central 